\title{
III. RESEÑAS
}

Fernando A. Blanco y Juan Poblete (Eds.). Desdén al infortunio. Sujeto, comunicación y público en la narrativa de Pedro Lemebel. Santiago de Chile: Editorial Cuarto Propio, 2010. 285 páginas.

Fernando Blanco y Juan Poblete han reunido en este tomo trece artículos en los que se discute la importancia de la obra de Pedro Lemebel en el ámbito político y económico del Chile de la postdictadura. En la introducción, los editores explican la personalidad multifacética de Lemebel, así como los estudios críticos que se han hecho sobre este artista. A continuación se dividen los diferentes artículos en tres secciones: "La irreverencia de la primera persona", "Las trampas de la voz" y "Las colonias de la sangre". Finalmente, se ofrece a modo de conclusión una entrevista con el escritor Pedro Lemebel titulada "Una ironía que es el sí pero no tanto..." dirigida por Fernando Blanco. Como sugiere el título, el libro se enfoca en tres temas, -sujeto, comunicación y público- en la narrativa de Pedro Lemebel, siendo el eje conductor el enfoque en el neoliberalismo y sus efectos en el sujeto chileno categorizado como minoría sexual que revela identidades diversas.

Carlos Monsiváis inicia el libro con un título en forma de diálogo con el escritor chileno "Pedro Lemebel: «Yo no concebía cómo se escribía en tu mundo raro» o del barroco desclosetado" en el que discute la poética de Lemebel como performer y cronista. Al referirse a las acciones y obras de Lemebel en cuanto a la política y sociedad chilena, Monsiváis hace una analogía con otros escritores de América Latina entre los cuales destacan Novo, Pellicer, Villarrutia, Ramos y Otero. De esta manera, Monsiváis traza una historia literaria de la escritura homosexual en América Latina.

El segundo artículo, "La Cigarra no es un bicho" de Adrián Cangi, revela un sujeto desplazado en las crónicas de Lemebel tanto por los deseos homoeróticos como por la desdicha homosexual y proletaria.

Jean Franco, en "Pedro Lemebel. El perpetuo enamorado" se enfoca principalmente en la obra Adiós mariquita linda (2005) y plantea como objetivo de esta crónica la manifestación de los modos de instrumentalización económica y biopolítica de los cuerpos.

Francine Masiello se pregunta “¿Por qué leer a Lemebel?” y responde en forma de carta dirigiéndose al mismo autor. Se enfoca en el cuerpo de los textos de Lemebel que relaciona con el cuerpo humano que éste exhibe en sus performances. Se refiere a sus textos como un cuerpo denso que construye "otra memoria" (67). Así, Masiello coincide con los demás críticos en que esta otra memoria corrige el neoliberalismo pero indirectamente y siempre entretejiéndolo con la sensualidad. Además presenta que los lectores de Lemebel no son exclusivamente feministas, gays y profesores universitarios, sino que su "cuerpo-texto" (68) traspasa estas etiquetas sociales y sexuales. 
En su ensayo, Fernando Blanco indaga sobre la figura del homosexual y destaca que para Lemebel la crisis no ofrece formas de identificación para todos los sujetos de la sociedad chilena. Igualmente, enfatiza que el discurso travesti se contrapone a la regulación de la moral y de la memoria de la época postdictatorial.

Marta Sierra, por medio del análisis del libro De Perlas y cicatrices y con la ayuda de varios teóricos de los estudios culturales (Walter Benjamin, Jesús Martín-Barbero, Guillermo Sunkel, Eugenio Tironi), cuestiona la eficiencia/solvencia política del intelectual-escritor. Asimismo, enfatiza el contraste entre la industria cultural de la dictadura y la postdictadura en esta obra. Como Blanco, Sierra reconoce que Lemebel recurre al travesti por su marginalidad social y genética para elaborar una fuerte crítica a las narrativas totalizadoras.

Juan Poblete destaca dos Lemebeles (136), un personaje local y una figura nacional. Al analizar De Perlas y cicatrices: Crónicas radiales (1998) y Zanjón de la aguada (2003) sobresale en el primer Lemebel "la denuncia y el testimonio" (141) en el cual lo local y 'la loca' negocian entre lo nacional y lo global, mientras que en el segundo Lemebel aparece la voz autobiográfica del autor que sin intermedios consigue mediar entre lo local y lo global.

Luis E. Cárcamo-Huechante identifica en las crónicas de Lemebel diferentes ciudadanías económicas, sociales y culturales en varias épocas chilenas y se enfoca en el mundo barrial del Santiago. Al analizar la crónica "Violeta persa, acrílica y pata mala", se enfoca en el mundo de un mercado popular de Santiago llamado el Persa Bío-Bío en el que se juntan productos reciclados con mercancías importadas de baja calidad. Esto es analizado como marca del neoliberalismo chileno que abrió irresponsablemente las puertas del comercio nacional. Cárcamo apunta la doble dislocación (económica y literaria) presente en la obra de Lemebel y así consigue la "barrialización del discurso letrado chileno y latinoamericano" (178).

Bernardita Llanos se enfoca en la figura de la madre en la escritura del autor, tomando como punto de partida la imagen de la madre en la cultura audiovisual y musical chilena e internacional. Al examinar varias figuras de la madre en los libros Loco Afán. Crónicas de sidario (1996), Zanjón de la Aguada (2003) y Tengo miedo torero (2001), Llanos apunta sobre los lugares y los valores que la madre ocupa en la cultura chilena que Lemebel trasmuta y adapta para forjar la Loca lemebeliana con varios matices. Asimismo, Llanos enfatiza que estas figuras maternales lemebelianas no están forjadas sin objetivo político sino que el artista chileno les otorga siempre un espacio amplio en la vida pública.

Nelly Richard se ocupa del concepto de viaje en las crónicas de Lemebel y lo conecta estrechamente con el travestismo. Al indagar en Adiós mariquita linda que desde el título implica una permutación, Richard se enfoca en la dislocación entre el nuevo sistema neoliberal y lo nacional chileno, sin dejar de lado la memoria histórica, ya que desde la misma portada del libro (Lemebel en travesti) se alude tanto a los desaparecidos políticos como a las injusticias que sufren las minorías sexuales en Chile.

Ángeles Mateo del Pino se enfoca en la escritura del sida y su importancia al enfatizar el cambio cultural, político y social que ha suscitado esta terrible enfermedad. Al comparar Europa, Estados Unidos y Latinoamérica revela los nuevos sujetos que se establecen 
durante la explosión del sida. En consonancia con el resto de los artículos, la autora nota que Lemebel inscribe la enfermedad en la política y la economía: “. . . pues así se hace más patente esa pulsión de muerte que, de nuevo, se liga a lo socioeconómico" (233).

Por su parte, Diana Palaversich explora la postura de Lemebel en cuanto a la diferencia entre el discurso homosexual proletario latinoamericano y el norteamericano y muestra que el discurso latinoamericano homosexual se niega a aceptar un modelo gay global en la escritura de Lemebel. Al conectar la homosexualidad con los problemas político sociales, se presenta el discurso gay latinoamericano con una doble función, la lucha por los derechos de las minorías sexualesy una crítica social aguda. De esta manera, con sus crónicas, Lemebel destaca “. . . aquello que perturba social y sexualmente” (247).

Mabel Moraña destaca el carácter neobarroco de la obra de Lemebel, puesto que sus textos se mueven entre varios géneros literarios, desde los más cultos hasta las formas literarias más marginales. Moraña hace hincapié en la desauratización de la obra de Lemebel y demuestra cómo su obra explora todos los límites permitidos por la palabra. Al usar los conceptos de Deleuze diferencia y repetición (271), la negatividad (272) de Lamborghini y el concepto de ruina (275) de Benjamín, Moraña insiste en que la obra de Lemebel es una repetición de las diferencias, pero afirma que en esta obra lo político abarca el ámbito social y el sexual.

La conclusión de este libro viene en forma de entrevista. En ella, Lemebel habla sobre los temas discutidos en los artículos que componen el libro: el sida, el neoliberalismo, la diferencia entre el gay estadounidense y la loca latinoamericana con énfasis en el libro Tengo miedo torero.

A través de estos trece artículos que profundizan en la obra de Pedro Lemebel, se presenta al lector la perspectiva chilena en cuanto a la homosexualidad, travestismo y a las identidades hibridas que se forman tanto como resultado de la política neoliberal como debido al estatus de minoría sexual. En definitiva, este libro constituye el estudio más completo sobre la obra de Lemebel, presenta el contexto histórico en el que está ubicada y da a conocer el amplio aporte de este autor en la lucha por los Derechos Humanos.

\author{
Mirela Butnaru \\ Denison University \\ mbutnaru@ualberta.ca
}

